\title{
New Technology of Combined Machining of Aluminium Alloys
}

\author{
Nikolay DOVZHENKO ${ }^{1}$, Sergey SIDELNIKOV ${ }^{1, \mathrm{a}^{*}}$, \\ Ivan DOVZHENKO ${ }^{1}$, Roman GALIEV ${ }^{1}$ \\ ${ }^{1}$ Siberian Federal University, Russia, 660025, Krasnoyarsk, Krasnoyarskiy Rabochiy ave., 95 \\ ae-mail: sbs270359@yandex.ru
}

Keywords: combined processes, aluminium alloys, casting, rolling, extruding, mechanical properties, stressstrain state.

\begin{abstract}
Basic information and research results of the process combined rolling-extruding have been represented, which have been used to create new energy-saving technologies for obtaining of long deformed semi-finished products of small cross-section. It has been shown that such combined processing technologies may be applicable for the machining of low ductility and low-tech aluminium alloys with high metal yield and high productivity.
\end{abstract}

\section{Introduction}

Growth in demand for long-length deformed semi-finished products of small cross-section of aluminium and aluminium alloys (rolled wire, rods and wire) led to the creation of new combined technologies of machining with using a continuous casting process and base metal forming operations - rolling and extruding [1-4]. Such a technique is implemented, for example, when the billet obtained using a rotary mold, and then rolled in the casting-rolling aggregates (CRA) or subjected to continuous extrusion at Conform units [5-6]. In this case, the metal machining processes are arranged sequentially, and only after one of them start next process. Combined process is more complex and is characterized by separation the basic processes in time and space [1]. Thus one of the machining stages can be a combination of two or more basic operations, at which there is integral imposition of loads in a deformation zone, sometimes with the change of the direction of metal flow. An example of this process can be considered a combined rolling-extrusion (CRE) when the metal of billet is pressed in a closed caliber of rolls, extruded before the matrix which overlapping gauge at the exit from the rolls, and subsumed by the instrument of active friction forces, is forced through the die aperture with a predetermined shape and size of extruded product [1] (Fig. 1). Thus the process is carried out in a continuous manner, and the resulting semifinished product is wound at a receiving device (reel). The use of bar rolling operation allows creating continuity of machining and the necessary strength of the active friction for extrusion of the finished product. Extrusion allows obtaining defined by the matrix configuration and sizes of products with high degrees of deformation [7-10] which makes it possible to produce them in one rolling mill for one cycle of machining.

Thus, the combination of these operations with the continuous casting can significantly reduce the number of technological processes and reduce labor intensity and energy intensity of technological process. This is especially relevant for low ductility and low-tech alloys, which are difficult to deform using traditional machining methods, therefore, in practice, for the manufacture of semi-finished products from these alloys have to use the discrete extruding methods with obtaining products of limited length on high-power extruders. Available high performance castingrolling aggregates are focused mainly on the production of circular cross-section rod made of aluminium mark A5E and A7E or alloy AVE, as the instrument of CRA roll It is not designed for rolling aluminum alloys with higher strength properties.

\section{Theory, technical and technological developments}


With the introduction of the combined technologies for the production of long products is provided with a number of technical and economic advantages [11, 12], the main of which are as follows:

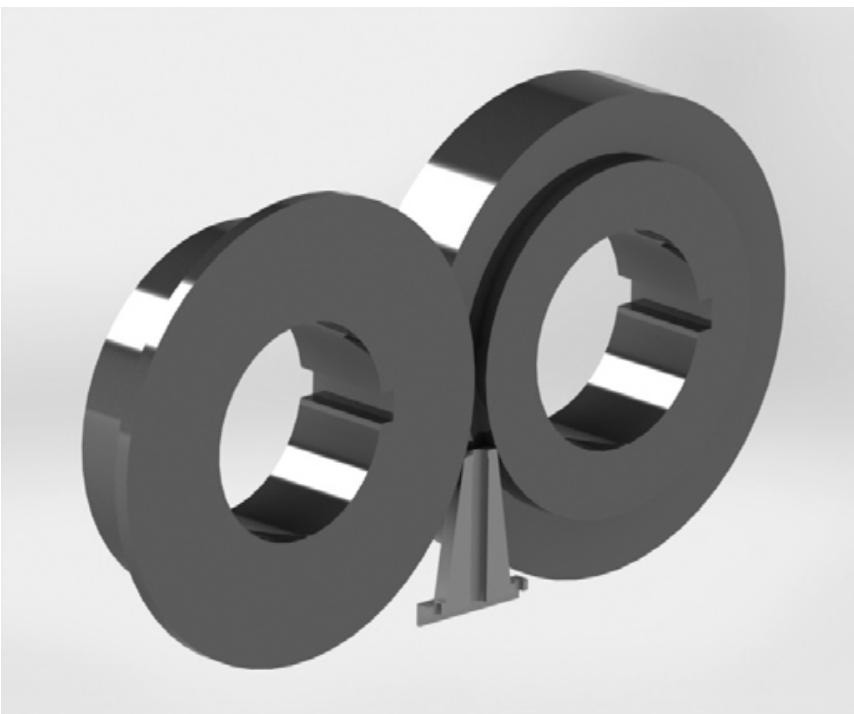

a



b

Fig. 1. Scheme of instrumental unit (a) and process (b) of combined rolling-extrusion

1. Continuity. Equipment and metal machining process for maximum performance should ensure the continuity of the technological chain from the obtaining the melt to the reeling of the finished product. The capacity of one unit for combined machining can reach 2,5 - 4 tons per hour.

2. The maximum degree of deformation in a single machining step. Almost all kinds of metal forming processes (excluding extrusion) characterized of multijunction, that is, to achieve the total strain in obtaining final products of small cross-section is necessary to break up deformation. In the production of rods by methods of bar rolling, including as part of the casting-rolling aggregates, the degree of deformation per passage compared to extrusion so low that the number of mills and passes even when rolling on continuous mills reaches 15-20 and more. At combined machining of metal deformation occurs in one deforming unit rolling-extrusion in a single pass.

3. Low power consumption of machining process. Almost all metal-working equipment is characterized by high energy intensity. This also applies to horizontal hydraulic presses, which are used to drive the pump and accumulator stations and multistand rolling mills with a group or an individual drive. Through the use of active friction forces power consumption of combined machining is reduced to 5-10 time compared to traditional types of production.

4. The minimum size of the equipment. Should be a minimum and ensure that all technological operations. For extruding equipment and casting-rolling aggregates equipment line length makes 50-70 meters. Dimensions of combined machining unit can be reduced by 2-5 times with the maximum dimension for the length may be 12 meters.

5. Quick changeover of equipment and the flexibility to move from one type of profile to another. High-performance methods for the production of a small cross-section of aluminum alloys by using the casting-rolling aggregates, it would seem, once solved all the problems on the creation of integrated machining lines. However, for the mini-production unit CRA can give cost-effective results only for large production volumes. In this slight change profile shape leads to the need of change for calibration rolls and manufacture of a new instrument (rolls) with other calibration. The combined machining may be used for smaller batches of orders, with the transition from one type of profile to another attained changing only the matrix.

6. High metal yield. Should be maximized, thus, the more technological processes, the greater the loss of metal yield. The yield during combined machining can be up to $90-95 \%$ by reducing losses at scraps and press residue. 
7. Ability to machining of different aluminum alloys. Almost all of the casting-rolling aggregates operating at the present time designed to receive rolled wire from aluminium A5E, A7E. Combined machining technology through the use of favorable schemes of the stress-strain state and the alternating deformation make it possible to obtain high-quality semi-finished products of low-tech and low-plasticity alloys.

In this regard, the development and introduction of new technologies of production of long semifinished products from aluminium alloys is an urgent task for the metallurgical industry. To solve this problem, the authors developed mathematical and computer model of the process CRE, allowing establishing metal forming regularities and identifying energy-power parameters of the process for a variety of combined machining units (Table 1).

Table 1 The data for calculating the feasibility and energy-power parameters of the process CRE

\begin{tabular}{|l|c|c|c|c|}
\hline \multicolumn{1}{|c|}{ Value } & $\begin{array}{c}\text { Unit } \\
\text { CRE-200 }\end{array}$ & $\begin{array}{c}\text { Unit } \\
\text { CCRE-2,5 }\end{array}$ & $\begin{array}{c}\text { Unit } \\
\text { CCRE-4 }\end{array}$ & $\begin{array}{c}\text { The } \\
\text { dimensionless } \\
\text { parameter }\end{array}$ \\
\hline Roll diameter with protrusion $D_{1}, \mathrm{~mm}$ & 214.0 & 462.0 & 428.0 & - \\
\hline Roll diameter with groove $D_{2}, \mathrm{~mm}$ & 164.0 & 394.0 & 428.0 & - \\
\hline Minimum height gauge $h, \mathrm{~mm}$ & 7.0 & 10.0 & 19.0 & - \\
\hline Average diameter of the rolls $D_{0}, \mathrm{~mm}$ & 189.0 & 428.0 & 428.0 & $A=\frac{D_{0}-h}{h}$ \\
\hline The width of the caliber $b, \mathrm{~mm}$ & 15.0 & 22.0 & 42.0 & $\tilde{b}=\frac{b}{h}$ \\
\hline Starting billet height $h_{0}, \mathrm{~mm}$ & 14.0 & 20.0 & 42.0 & $\tilde{h}_{0}=\frac{h_{0}}{h}$ \\
\hline Starting billet width $b_{0}, \mathrm{~mm}$ & 14.0 & 20.0 & 40.0 & $\tilde{b}_{0}=\frac{b_{0}}{h}$ \\
\hline Matrix surface height $h_{M}, \mathrm{~mm}$ & 20.0 & 25.0 & 31.0 & $\tilde{h}_{\mathcal{M}}=\frac{h_{\mathcal{M}}}{h}$ \\
\hline Diameter of extruded product $d, \mathrm{~mm}$ & 9 & 9 & 9 & $\tilde{h}_{1}=\frac{d}{h}$ \\
\hline
\end{tabular}

\section{Theoretical research}

Theoretical analysis of the process combined rolling-extrusion [13] have shown, that for realization of the process should be carried out the power balance condition, that is the total capacity of subsumed active friction forces $N_{a}$ must be equal (or more) to power of reactive forces $N_{r}$, spent on the implementation of deformation and overcoming friction in the deformation zone and instrument surfaces

$$
N_{a}-N_{r}=0 .
$$

If this condition is not fulfilled, rolls can slip relative to the billet and the process of extruding metal becomes impossible. As a assessment criterion of the process feasibility adopted a conditional coefficient of power reserve $K_{N}$, calculated as the ratio of power $N_{a}$ to power $N_{r}$, and if its value is greater than 1 , extrusion of metal through a matrix becomes possible and its probability increases with this ratio. 
Fig. 2 shows data for this calculation method for obtaining rods made of aluminium alloy 6063 depending on various conditions of contact friction with a metal roll and the matrix $\left(\psi_{M}\right.$ - rate of friction on the surface of the matrix, $\psi_{n}$ - rate of friction on the belt of matrix $\psi_{b}$ and $\psi_{c m}$ - friction indices, respectively, on the surface of roll and the walls of roll with a groove) by the method of combined rolling-extrusion on different units (Table 1).

Analysis of the data shown in Fig. 2 shows that the diameter of the rolls (Fig. 2 a, b) a significant impact on increasing the feasibility of the process. However with increasing gauge sizes for one and the same of the rolls diameter (Fig. 2 b, c) coefficient of power reserve $K_{N}$ decreases, that should be considered when designing combined machining units.

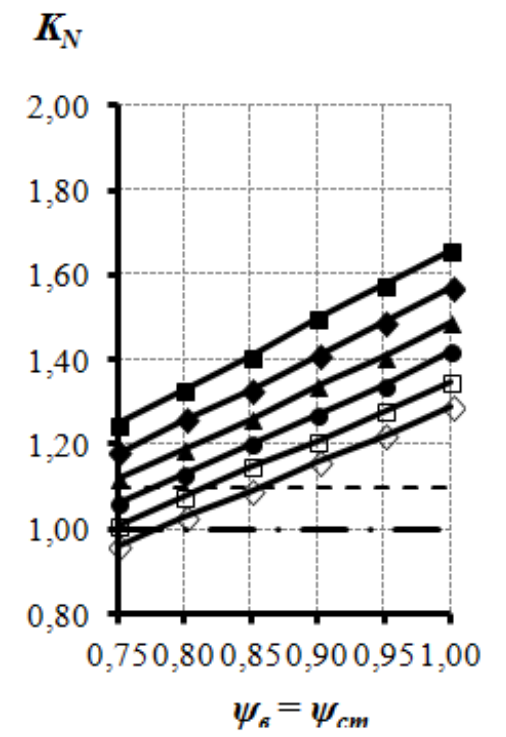

$a$

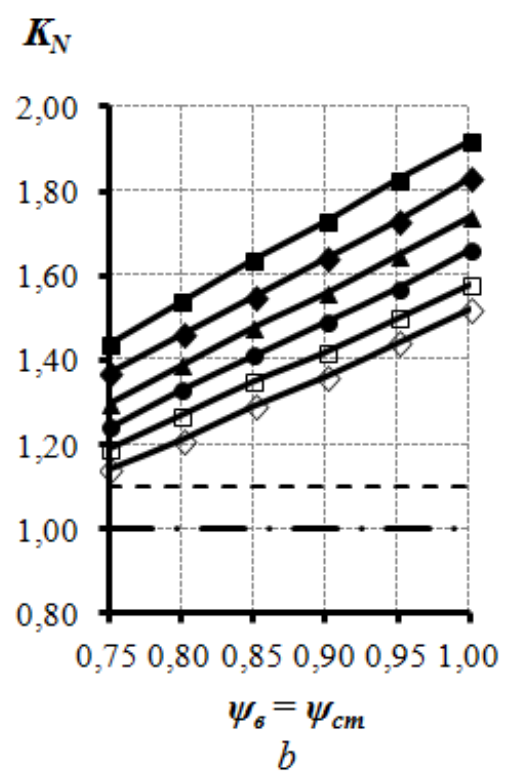

\section{$\boldsymbol{K}_{\mathrm{N}}$}

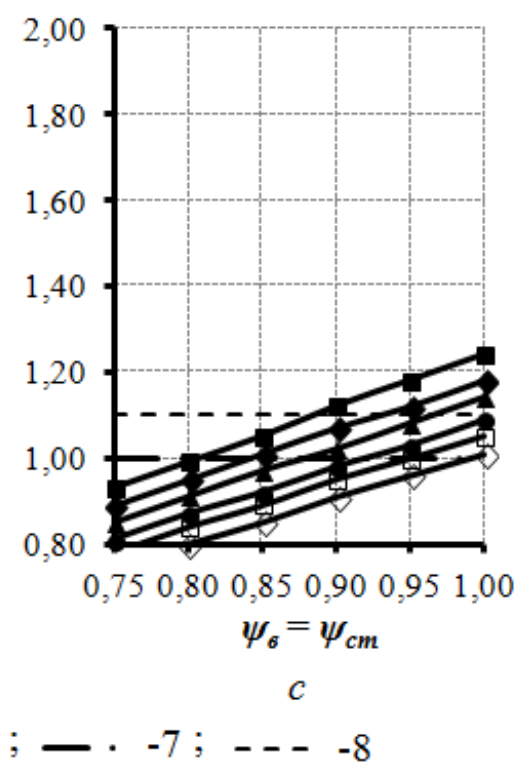

Fig. 2. Coefficient of power reserve $K_{N}$ changing depending on the conditions of friction: a - for unit CRE-200, b - for unit CCRE-2,5; c - for unit CCRE-4; $1-\psi_{M}=\psi_{n}=0,50 ; 2-\psi_{M}=\psi_{n}=0,55 ; 3-\psi_{M}=\psi_{n}=0,60 ; 4-\psi_{M}=\psi_{n}=0,65$;

$5-\psi_{M}=\psi_{n}=0,70 ; 6-\psi_{M}=\psi_{n}=0,75 ; 7$ - theoretical limit of process feasibility; 8 - boundary process feasibility

In order to analyze metal forming and energy and power parameters of combined machining process a mathematical model of rolling-extrusion in a closed box-caliber was built [1] by using system of equations, including the power balance equation and the equation of the variational principle of minimum total power

$$
\delta\left(N_{\text {in }}+N_{c}-N_{\text {sl }}-N_{\text {roll }}\right)=0,
$$

where $N_{\text {in }}$ - power of internal forces; $N_{c}$ - power of cutoff forces; $N_{s l}$ - Power friction stresses on the sliding speeds; $N_{\text {roll }}$ - input power of rolls.

The basic elements of the mathematical model are the geometric model describing the center plastic deformation with an accuracy of variable parameters, kinematically possible velocity field and the boundary conditions.

To determine the components of the total power used formulas

$$
N_{\text {in }}=\int_{V} 0,58 \sigma_{S} H d V, N_{c}=\int_{F_{c p}} 0,58 \sigma_{S}\left|V^{+}-V^{-}\right| d F, N_{s l}=-\int_{F_{\mathrm{K}}} \tau_{m p} v_{c \kappa} d F, N_{\text {roll }}=\int_{F_{\mathrm{\kappa}}} \tau_{m p}^{*} v_{B} d F \text {, }
$$


where $H$ - the intensity of shear strain rates; $\sigma_{s}$ - deformation resistance of the metal; $V^{+}, V^{-}$ projection of the metal flow velocity at tangent plane to the velocity of the discontinuity surface $F_{c p j}$, respectively, the inner and outer sides of the surface; $n$ - number of discontinuity surfaces velocities; $\tau_{m p}$ - shear stress; $\tau_{m p}^{*}$ - stress component of the total friction at a tangent to the circumference roll at any point of the contact surfaces.

The solution of the variational problem it possible to obtain a numerical dataset largest forces acting on the matrix $P_{\text {matr }}$ and rolls $P_{\text {roll }}$, depending on the dimensionless parameters of the process rolling-extruding, and the formula for calculating desired quantities:

for the force acting on the matrix

$$
\begin{aligned}
& P_{\text {matr }}=\frac{0,12 \sigma_{s}(A-11,5)}{\sqrt{3}}\left[2 \ln \mu(\tilde{b}+1)\left(L_{1}+L_{2}\right) h-\frac{\tilde{b}}{(A+1)}\left(L_{1}^{2}+L_{2}^{2}\right)+\right. \\
& \left.\frac{\ln \mu}{2 h(A+1)}\left(L_{1}^{3}+L_{2}^{3}\right)-\frac{\tilde{b} h}{12(2 h A+2 h)^{3}}\left(L_{1}^{4}+L_{2}^{4}\right)+\frac{\ln \mu}{30(2 h A+2 h)^{3}}\left(L_{1}^{5}+L_{2}^{5}\right)\right] ;
\end{aligned}
$$

for the force acting on the rolls

$$
\begin{aligned}
& P_{\text {roll }}=(1,7-0,38 A) \sigma_{S} \frac{4 \tilde{b} h}{\sqrt{3}}\left[\left(\frac{h}{12 h(A+1)}-1\right)\left(L_{1} \ln \left(2 h^{2}(A+1)+L_{1}^{2}\right)+L_{2} \ln \left(2 h^{2} A+2 h^{2}+L_{2}^{2}\right)\right)\right. \\
& -\left(L_{1}+L_{2}\right)\left(\frac{h}{12 h(A+1)}-1\right) \ln \left(2 h^{2}(A+1)\right)++\frac{3 \ln \mu}{2 \tilde{b} h}\left(L_{1}^{2}+L_{2}^{2}\right)-\frac{\left(L_{1}^{3}+L_{2}^{3}\right)}{12(2 h A+2 h)^{2}}+\frac{2 \tilde{b} h}{\sqrt{3}} \\
& \left.+\frac{\ln \mu}{\tilde{b} h}\left(\frac{\tilde{b} h \sqrt{2 h(A+1)}}{\sqrt{h}}-\sqrt{2 h^{2}(A+1)}\right) \times\left(L_{1} \arctan \frac{L_{1}}{\sqrt{2 h^{2}(A+1)}}+L_{2} \arctan \frac{L_{2}}{\sqrt{2 h^{2}(A+1)}}\right)\right],
\end{aligned}
$$

where $L_{1}$ - the length of the capture zone during rolling, $L_{2}$ - length zone of extruding, $\mu$ reduction ratio during extrusion.

Using the developed mathematical model calculated the energy and power parameters for machining one of the most used in industry aluminium alloy 6063 (Table 2) at laboratory units CRE-200 and CCRE-2,5, as well as industrial prototype unit CCRE-4 from Irkutsk aluminium smelter (Table 1).

The calculation was made for the real process conditions of combined machining, while temperature of the billet was varied $\left(T_{b}=400{ }^{\circ} \mathrm{C}\right.$ and $\left.540{ }^{\circ} \mathrm{C}\right)$, the rotational speed of the rolls (values of strain rate amounted $\xi=0,23$ and $0,81 \mathrm{sec}^{-1}$ ), and the degree of deformation (extraction rates during extrusion was equal $\mu=4,4 ; 7,3$ and 14,3 ).

The values of energy-power parameters for unit CRE-200 are shown in Table. 2.

Table 2 - Energy-power parameters during machining of aluminium alloy 6063 on the units of combined machining

\begin{tabular}{|c|l|c|c|c|c|c|c|}
\hline \multirow{2}{*}{ Parameter } & \multicolumn{3}{c|}{$T_{b}=400{ }^{\circ} \mathrm{C}$} & \multicolumn{3}{c|}{$T_{b}=540{ }^{\circ} \mathrm{C}$} \\
\cline { 2 - 8 } & $\mu=4.4$ & $\mu=7.3$ & $\mu=14.3$ & $\mu=4.4$ & $\mu=7.3$ & $\mu=14.3$ \\
\hline \multicolumn{7}{|c|}{ Unit CRE-200 } \\
\hline \multirow{2}{*}{$\xi=0.23 \mathrm{sec}^{-1}$} & $P_{\text {roll, } \mathrm{kN}}$ & 121 & 127 & 134 & 59 & 62 & 65 \\
\cline { 2 - 8 } & $P_{\text {matr }} \mathrm{kN}$ & 71 & 95 & 128 & 35 & 46 & 62 \\
\hline \multirow{2}{*}{$\xi=0.81 \mathrm{sec}^{-1}$} & $P_{\text {roll }}, \mathrm{kN}$ & 152 & 160 & 169 & 75 & 79 & 83 \\
\cline { 2 - 8 } & $P_{\text {matr }, \mathrm{kN}}$ & 90 & 120 & 161 & 44 & 59 & 80 \\
\hline \multicolumn{7}{|c|}{ Unit CCRE-2,5 } \\
\hline
\end{tabular}




\begin{tabular}{|c|c|c|c|c|c|c|c|}
\hline \multirow{2}{*}{$\xi=0.23 \mathrm{sec}^{-1}$} & $P_{\text {roll }, \mathrm{kN}}$ & 249 & 263 & 276 & 121 & 128 & 134 \\
\hline & $P_{\text {matr }, \mathrm{kN}}$ & 100 & 134 & 180 & 49 & 65 & 88 \\
\hline \multirow{2}{*}{$\xi=0.81 \mathrm{sec}^{-1}$} & $P_{\text {roll }, \mathrm{kN}}$ & 312 & 330 & 347 & 155 & 163 & 172 \\
\hline & $P_{\text {matr, }, \mathrm{kN}}$ & 126 & 168 & 226 & 62 & 83 & 112 \\
\hline \multicolumn{8}{|c|}{ Unit CCRE-4 } \\
\hline \multirow{2}{*}{$\xi=0.23 \mathrm{sec}^{-1}$} & $P_{\text {roll }, \mathrm{kN}}$ & 621 & 656 & 690 & 302 & 319 & 335 \\
\hline & $P_{\text {matr }, \mathrm{kN}}$ & 313 & 418 & 562 & 152 & 203 & 273 \\
\hline \multirow{2}{*}{$\xi=0.81 \mathrm{sec}^{-1}$} & $P_{\text {roll }, \mathrm{kN}}$ & 781 & 824 & 867 & 386 & 407 & 428 \\
\hline & $P_{\text {matr }, \mathrm{kN}}$ & 394 & 526 & 707 & 195 & 260 & 349 \\
\hline
\end{tabular}

Analysis of calculated data showed that for caliber with dimensions in minimum cross-section $7 \times 15 \mathrm{~mm}$ and temperature $400{ }^{\circ} \mathrm{C}$ force on the rolls does not exceed $200 \mathrm{kN}$, and the force on the matrix does not exceed $182 \mathrm{kN}$. For comparison, the force of horizontal industrial hydraulic press used to obtain rods of the same diameter and alloy is $8000 \mathrm{kN}$. Increasing the temperature to $540{ }^{\circ} \mathrm{C}$ leads to a further reduction of efforts, and growth of a strain rate (speed of rotation of the rolls) to the growth of energy-power parameters of the process CRE because of speed metal hardening.

\section{Conclusion}

The experimental results $[1,14]$ of form changing, structure and properties of metal, as well as the energy-power parameters of the process CRE confirmed the results of theoretical research, and they were made for the various series of aluminium alloys $1 \mathrm{XXX}, 3 \mathrm{XXX}, 4 \mathrm{XXX}, 5 \mathrm{XXX}, 6 \mathrm{XXX}$, 8XXX and marks AD1 (1230), AD31 (6063), AD35 (6082), AK5, AK12, AMg6, AV9, and also systems Al-Ti-B, Al-Zr, Al-Sc and others.

Based on the results of theoretical and experimental studies methods and apparatus for combined machining have been proposed. These include basic operations as casting into roller mold, rolling and extrusion. The operations of casting and rolling-extruding can be separated in time or combined in one deforming zone. This gives the possibility of varying the machining methods depending on the properties and rheological characteristics of aluminium alloys. Furthermore, there is the option of using as a casting aggregate unit with electromagnetic mold, which can significantly improve the structure of obtained cast billet, improve mechanical properties and reduce its energy-power parameters for subsequent machining.

Technical decisions on these methods of combined machining and equipment for their implementation are protected by 25 patents of RF. At their base in the Siberian Federal University and a number of metallurgical plants set up laboratory and pilot-scale units of the combined machining, on which conducted a comprehensive study on form changing, stress-strained state of metal and energy-power parameters of new processes.

Thus, the further development of combined machining technology requires the introduction of proposed new technical and technological solutions in production to obtain a product in the form of long deformed semi-finished products from aluminium alloys at low cost and large savings in metal.

\section{References}

[1] S.B. Sidelnikikov, N.N. Dovzhenko, N.N. Zagirov, Combined and complex methods of machininbg non-ferrous metals and alloys, M.: MAKS PRESS, 2005.

[2] Avitzur B. Combining Extrusion and Rolling. Wire journal, 1975, P. 73-80.

[3] Pat. 3934446 USA, B 21 B 21/00. Methods of and apparatus for production of wire [Text]. B. Avitzur; 27.01.1976.

[4] Ryszard Grzyb, Joachim Jonca, Stanislav Kajzer. At attemp to compare a new process of "Rolling through the die" with the multipass rolling as exemplified by rolling of flat. Archiwim Hutnictwa, 1986, 31, № 3, P. 369-377. 
[5] Green D. The continuous extrusion forming of wire sections [Text]. TRG Report 2364 (S), Juli 1972.

[6] Scott K. Extrusion unit Conform ${ }^{\mathrm{TM}}$, aluminum waste and space technology. Tsvetnye metally. 2001, June. Special issue. - P. 91-93.

[7] Extruding. Reference manual. M. Bauser, G Sauer, K. Siegert. Trans. from the German by publishing license Aluminium Verlag Marketing \& Kommunikation GmbH, M.: «ALUSIL MV\&T», Moscow, 2009. - 918 p.

[8] Pradip K. Saha, Aluminum Extrusion Technology, ASM International, 2000.

[9] Shcherba V.N. Extrusion of aluminium alloys. - M.: «Intermet Engineering », 2001. - 768 p.

[10] Shcherba V.N. Technology of extruding methods [Text]. V.N. Shcherba, L.Kh. Raytbarg. - M.: Metallurgy, 1995. - $336 \mathrm{p}$.

[11] Loginov Yu.N. Energy saving in the extrusion process [Text]. Yu.N. Loginov, S.P. Burkin. Tsvetnye metally. - 2002. - №10. - P. 81-86.

[12] Sergeev V.M. Continious casting-extruding of non-ferrous metals [Text]. V.M. Sergeev, Yu.V. Gorokhov, V.V. Sobolev, N.A. Nesterov. - M.: Metallurgy, 1990. - 85 p.

[13]N. Zagirov, N. Dovzhenko, S. Sidelnikov, V. Bespalov, Computational-and-Experimental Evaluation of the Implementation Condition of Combined Rolling-Pressing Using the Power Balance Method Russian Journal of Non-Ferrous Metals, 2016, Vol. 57, №2, pp. 90-95.

[14] I. Matveeva, N. Dovzhenko, S. Sidelnikov, L. Trifonenkov, V. Baranov, E. Lopatina, Development and research of new aluminium alloys with transition and rare-earth metals and equipment for production of wire for electrotechnical applications by methods of combined processing. TMS Light Metals Issue Light Metals 2013 - At the TMS 2013 Annual Meeting and Exhibition. - 2013. - PP. 443-447. 